\title{
Experimental Approach and CFD Simulation of Battery Electric Vehicle Body
}

\author{
Tamer Nabil ${ }^{*}$, Abo-Bakr Helmy Omar, Tamer Mohamed Mansour \\ Mechanical Engineering Department, Suez Canal University, Ismailia, Egypt \\ Email address: \\ Tamer_mtc@yahoo.com (T. Nabil) \\ ${ }^{*}$ Corresponding author

\section{To cite this article:} \\ Tamer Nabil, Abo-Bakr Helmy Omar, Tamer Mohamed Mansour. Experimental Approach and CFD Simulation of Battery Electric Vehicle \\ Body. International Journal of Fluid Mechanics \& Thermal Sciences. Vol. 6, No. 2, 2020, pp. 36-52. doi: 10.11648/j.ijfmts.20200602.11
}

Received: March 12, 2020; Accepted: June 9, 2020; Published: June 20, 2020

\begin{abstract}
Aerodynamic is considered the most significant factor affecting on vehicles fuel consumption and power requirements even at low speed. For this reason, there are much interest and some modifications that decrease drag coefficient and reduce the aerodynamic effectiveness. This study aims to develop an electrical car body (ECB) to decrease the drag coefficient and study the reflection of this parameter in the power consumption rate in different operating speeds. Six different models for car bodies (Bendra, Magenta, Violet, Bluria, Aqua and Vectra) with same wheelbase, height, and track width dimensions are designed. The design of these models has done using Solidworks software by surface tools. Numerical results (frontal area, drag coefficient, drag area and drag force) for the six models are recorded and compared to choose the best designed body. According to results Vectra model is chosen as a best design. The power consumption is calculated for each model at different operating speeds using two different software, Solidworks flow simulation and ANSYS fluent. Experimental results are obtained by testing 3D printing model for the best efficient model with scale 1:25 at small subsonic open wind tunnel. The experimental results show good agreement with simulation results. Finally, Vectra simulation and experimental results are compared with the real electric and petrol cars to verify the competitive design for Vectra model.
\end{abstract}

Keywords: CFD, Vehicle Body, Drag, Wind Tunnel

\section{Introduction}

One of the main contributors to the greenhouse effect is the burning of fossil fuels for transportation and heating. The transport sector is currently the main consumer of fossil fuels. So car manufacturers are starting to implement a more sustainable approach when developing vehicles with the focus on electric vehicles in order to reduce the use of fossil fuels. A significant contribution to the energy consumption of vehicles comes from the air resistance that a vehicle is exerted to. For an electric vehicle, the air resistance can reach up to $48 \%$ of the total driving resistance at highway speeds [1]. Aerodynamic Design of cars is crucial as it directly affects the fuel economy \& stability in motion.

There are many investigations that tried to study the aerodynamic behavior around heavy vehicles and tried to find out how to reduce the power consumption [2-5]. The studies tried to find out a better way to improve the vehicle performance throughout modifying the shape of the vehicle.
Literature on electric vehicle bodies has analyzed several factors affected on drag coefficient and power consumption of them.

Wang, et al. [6], investigated the aerodynamics performance of Model S vehicle of TESLA using 3D scanner and STAR-CCM+ (software of Siemens). The drag coefficient and local flow field data of the vehicle in different working conditions are simulated and the mechanism of flow is analyzed. Gupta, et al. [7], analyzed by CFD the aerodynamics package of the race car which includes a front wing, a rear wing and an under tray. Simulations of a contoured under tray and simplified full body model were presented. Janson, et al. [8], presents the results of numerical analysis of aerodynamic characteristics of a sports car equipped with movable aerodynamic elements. The calculations were performed with the help of the ANSYSFluent CFD software.

Wang, et al. [9], investigated the effect of the power battery pack installed in the classis of the electric vehicle on 
aerodynamic performance, take the SAE-B model as object. Using CFD simulation method, the effect of battery pack on the flow field of the vehicle structure caused by the size of battery pack was studied. Ravelli, et al. [10], investigated 2017 F1 car aerodynamics from a numerical point of view by using an open-source code (OpenFOAM). The racing car performance is quantitatively evaluated in terms of drag, downforce, efficiency and front balance. Siva, et al. [11], investigated the aerodynamics characteristics of TOYOTA car model using ANSYS Fluent to determine the aerodynamic characteristics like pressure, down-force and drag. The external body of the car is modeled using Solidworks modeling software.

Parab, et al. [12], determined the lift and drag of the vehicle by the analysis of flow of air around it using ANSYS 14.5. Purevsuren, et al. [13], modeled the correct mesh size and, determined the varying $y+$ until further increases in the mesh yielded no difference accordingly the focusing on the effect of grid scheme and turbulence models on the CFD model of wind turbine airfoil. Czyż, et al. [14], presented the numerical analysis of the drag force generated on the body of a sports car, based on the CFD method in the ANSYS Fluent program.;

Vaidya, et al. [15], described the initial design and development of the front and the rear wing of a Formula SAE car. CFD analysis of front and the rear wing is also covered. Wind tunnel testing and on-track testing is being developed.

Taherkhani, et al. [16], presented the first experimental and computational investigation into the aerodynamics of emergency response vehicles and focuses on reducing the additional drag that results from the customary practice of adding light-bars onto the vehicles' roofs. A series of wind tunnel experiments demonstrate the significant increase in drag that results from the light bars. Cieslinski, et al. [17], Optimized the shape of car body to be used in Shell Eco Marathon race. Yuan, et al. [18], investigate the sensibility of aerodynamic characteristic to the underbody, and summarize the influence of aerodynamic attachments on the aerodynamic drag.

Rakibul, et al. [19], investigated on different aspects analysis of aerodynamic drag of racing cars and different drag reduction techniques such as rear under body modification and exhaust gas redirection towards the rear separation zones. The drag coefficient of the car under analysis is found to be 0.3233 and it is evident that the drag can be reduced up to $22.13 \%$ by different rear under-body modifications.

Singla, et al. [20], investigated the aerodynamic consideration in designing body for a solar car which is to participate in world solar challenge, the world's top solar car race. Shivam, et al. [21], investigated vortex generators was done to install immediately upstream of the flow separation point in order to control the separation of air flow above the car's window and improve the aerodynamic characteristics. Damissie, et al. [22], this computational analysis showed that there is possibility of improving the aerodynamic performance of bus by modifications in exterior design of bus body. Patil, et al. [23], investigated the benefits of Aerodynamic features around the BUS by reducing Cd which improves the fuel consumption. Optimization of BUS is carried out by adding spoilers and panels at rear portion. Parmar, et al. [24], experiment's objective is to analyze aerodynamic characteristics of passenger car using wind tunnel method and Computational Fluid Dynamics (CFD) approach.

Howell, et al. [25], modified a simple car body shape to include tapering of the rear upper body in both roof and sides that to investigate the effects of taper angle and taper length on drag and lift. Wind tunnel tests have been conducted on the model to investigate the drag benefits from rear body taper. Jessing, et al. [26], Investigated the new systems which were implemented during the recent wind tunnel upgrade as well as comparable computational fluid dynamics simulations. The wind tunnel measurements in unsteady crosswind conditions can be complemented by numerical simulations.

Pikula, et al. [27], presented the results of the numerical simulations of the air flow around the vehicle model compared to the experimental results. Pikula, et al. [28], investigated the drag coefficient of vehicle model in ratio of 1: 18 using open type wind tunnel with different air speed. The results of the air drag coefficient are compared to the same value of the real vehicle. Pal, et al. [29], proposed a concept car model which will face very small drag force and also to reduce the corresponding drag coefficient. Solidworks flow simulation is used to perform the computational analysis which is later verified by a subsonic open circuit suction type wind tunnel testing of the concept car model. Ahmad, et al. [30], examined the effect of different mesh parameters to optimize the mesh strategy for accurately estimating the drag of a ground vehicle using design of experiments (DOE). A simplified car model at three scales has been investigated and compared with results from the MIRA model wind tunnel.

Thabet, et al. [31], investigated the flow characteristics over a model car. The aim was to calculate the aerodynamic coefficients from the CFD simulation and compared them with the available experimental data. Vishwakarma, et al. [32], modified the sedan car model with deck lid spoiler and grooves in the back, to reduce the aerodynamic drag force. The designing of sedan car has done on SOLIDWORKS 2010 and analysis have done by using ANSYS 15 (FLUENT). Huminic, et al. [33], investigated the effect of the wheels on the body fitted with an underbody diffuser using a generic car model on wheels as a reference.

This study tried to find an efficient design focuses on the aerodynamics characteristics such as drag force for urban electric vehicles. The drag force and frontal area of the vehicle affect directly on vehicle power at various velocities. Six different car body models were designed and simulated to reach the minimum drag area. Experimental tests were implemented on the chosen body model. The study tried to find out a better way to improve the vehicle performance throughout modifying the shape of the vehicle and to improve aerodynamic performance of an urban electric 
vehicle by simple and robust means.

\section{Vehicle Body Design}

This part discussed the methods and procedures of designing the exterior body of an urban electric vehicle. In order to get best, comparison, and satisfying results, six urban vehicle bodies were designed taking into consideration the main dimensions are same for each model. The six models are designed with Solidworks 2016 CAD software using surface tools, and all images are rendering using KEYSHOT software as shown in Table 1. The main dimensions of the models; wheelbase $1600 \mathrm{~mm}$, height 1200 $\mathrm{mm}$ from ground, front track width $1100 \mathrm{~mm}$ and rear track width $950 \mathrm{~mm}$. Each design must cover all interior vehicle components. Vehicle models must meet the aerodynamics principles. The design reaches the minimum frontal area as possible. Final design not far away from urban vehicle shape. Final design is ready for manufacturing. The design of vehicle body models is based on the previous parameters, so there is a little bit of changes between each body like the final shape and total length. Table 1 shows the shape and dimensions of different six vehicle bodies; Bendra, Magenta, Violet, Bluria, Aqua and Vectra.

Table 1. Shape and dimensions of different vehicle bodies.

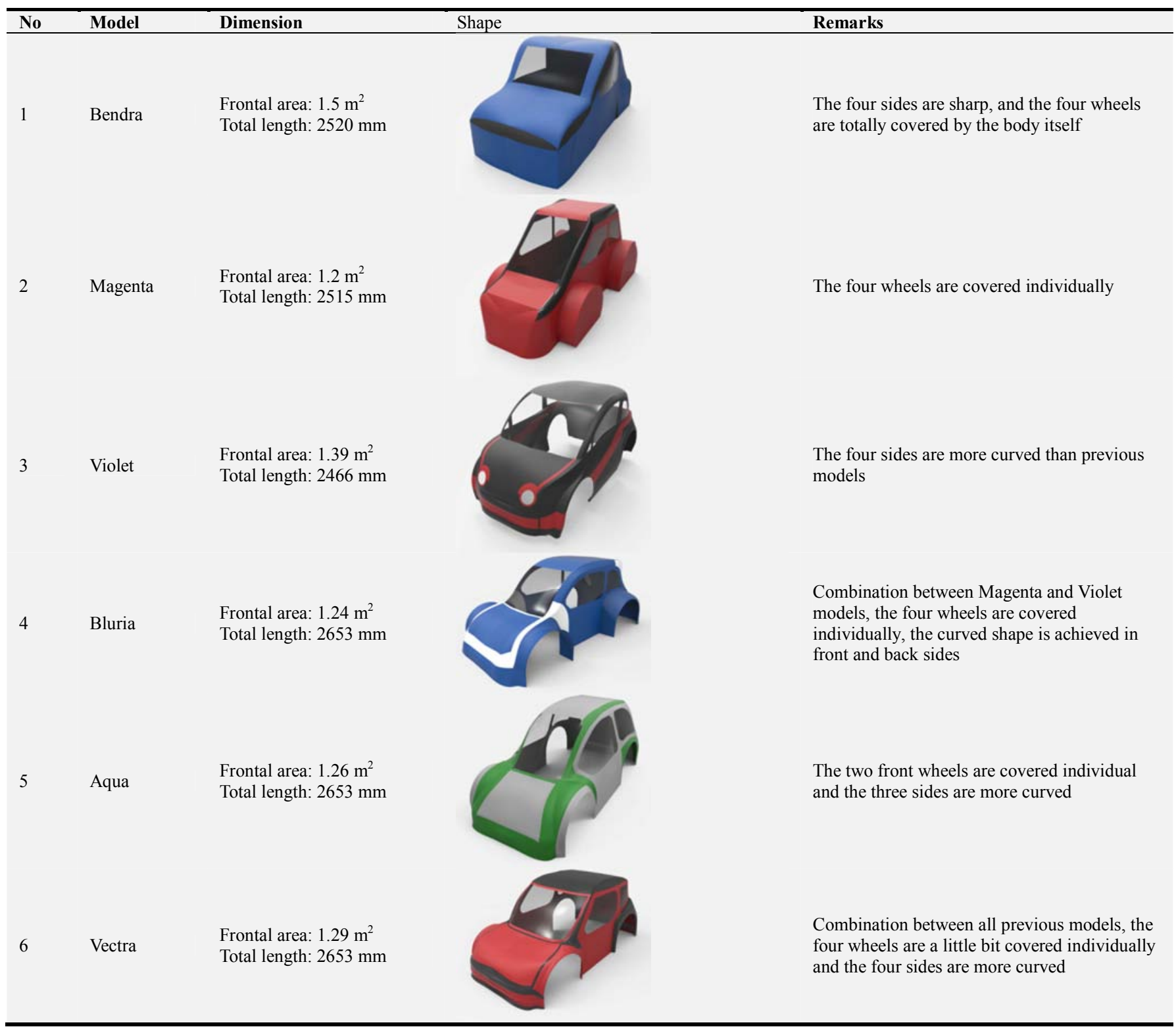

\section{CFD Analysis}

The studied parameters and model simplification are showed in Table 2. The computational fluid dynamics CFD analysis done by using two different softwares, Solidworks flow simulation and ANSYS fluent. 


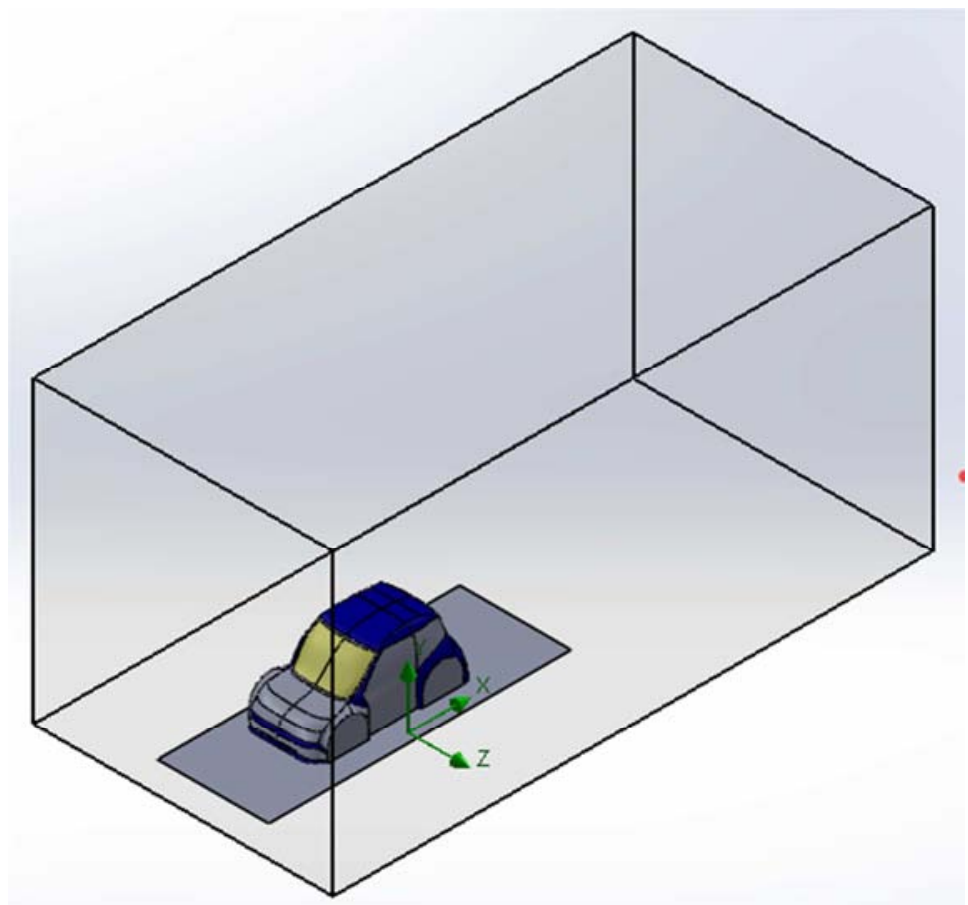

Figure 1. Computational domain size.

Table 2. Study parameters.

\begin{tabular}{ll}
\hline Unit system & SI $(\mathbf{m} / \mathbf{k g} / \mathbf{s})$ \\
\hline Pressure & $101325 \mathrm{~Pa}$ \\
Temperature & $293.2 \mathrm{k}$ \\
Velocity range & $0-30 \mathrm{~m} / \mathrm{s}$ \\
Flow type & Laminar and turbulent \\
Analysis type & External flow \\
Size of computational domain & $10 \mathrm{~m} * 5 \mathrm{~m} * 5 \mathrm{~m}$ \\
\hline
\end{tabular}

The analysis software need to simplify the model to accept the studied model and to reduce analysis time, so all vehicle body models are simplified which the model converted from surface model to solid model and filled all side gaps like wheels and ground gaps.

\section{Mathematical Model}

Drag coefficient

$$
C_{D}=\frac{D}{\frac{1}{2} \rho V_{\infty}^{2} A}
$$

Lift coefficient

$$
C_{L}=\frac{L}{\frac{1}{2} \rho V_{\infty}^{2} A}
$$

Power consumption

$$
P=D * V_{\infty}
$$

\section{Simulation Results}

\subsection{Solidworks Flow Simulation}

All models are simulated in Solidworks flow simulation at
$\mathrm{V}=30 \mathrm{~m} / \mathrm{s}$.

Table 3. Vehicle models results - Solidworks.

\begin{tabular}{lllll}
\hline & $\begin{array}{l}\text { Frontal } \\
\text { area } \mathbf{~ m}^{2}\end{array}$ & Cd & Drag area $\mathbf{~ m}^{2}$ & Power W \\
\hline BENDRA & 1.54 & 0.605185 & 0.960344 & 15882.53 \\
MAGENTA & 1.22 & 0.72812 & 0.920856 & 15229.68 \\
VIOLET & 1.43 & 0.407735 & 0.599326 & 9911.64 \\
BLURIA & 1.22 & 0.572499 & 0.70893 & 11724.72 \\
AQUA & 1.3 & 0.455167 & 0.594513 & 9832.38 \\
VECTRA & 1.37 & 0.400757 & 0.549038 & 9079.44 \\
\hline
\end{tabular}

The power data for the six models in Table 3 shows that the most effective model in power consumption is the VECTRA model. Which mean that when the VECTRA model go on the road at $\mathrm{V}=30 \mathrm{~m} 8$ 磅/s, the power consumption will be about $9 \mathrm{KW}$. The nearest vehicle models are AQUA and VIOLET del with $9.8 \mathrm{KW}$ and $9.9 \mathrm{KW}$ respectively. Table 3 also shows that the frontal area is not the main factor to determine the drag coefficient and power consumption, as we show the most effective model has a medium frontal area value compared with the other models and it has a minimum drag coefficient compared with the other vehicle body models. The following flow simulation results have been taken at $\mathrm{V}=30 \mathrm{~m} / \mathrm{s}$

Velocity streamlines for different bodies have different conFigureurations according to the body shape and dimensions, as shown in Figure 2. Flow separation is clear at certain points especially at sharp edges. All models nearly have smooth stream lines at the frontal area but at the rear areas the back flows are appeared due to under pressures at these locations. From the stream lines distribution, VECTRA design has the most preferred distribution. 


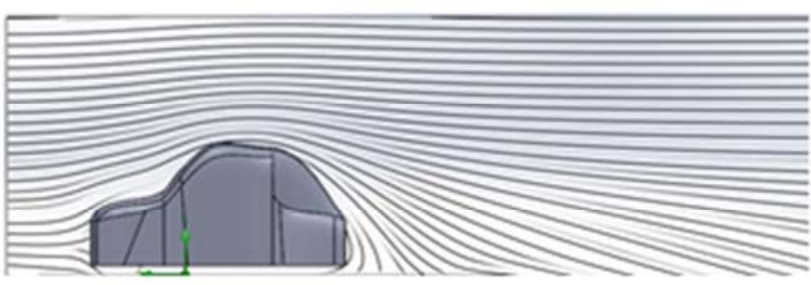

Bendra

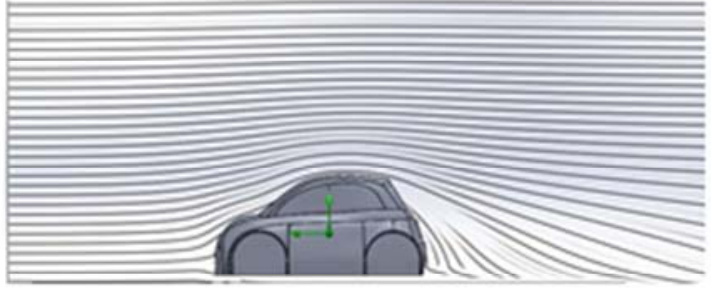

Violet

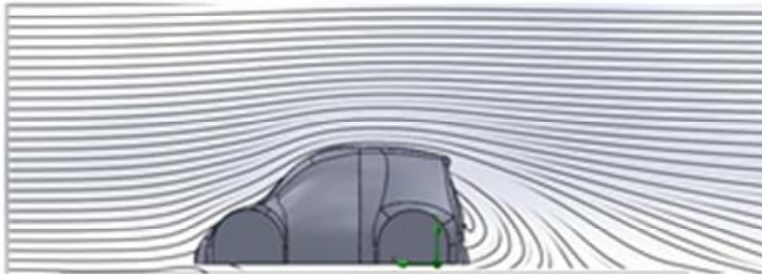

Aqqua

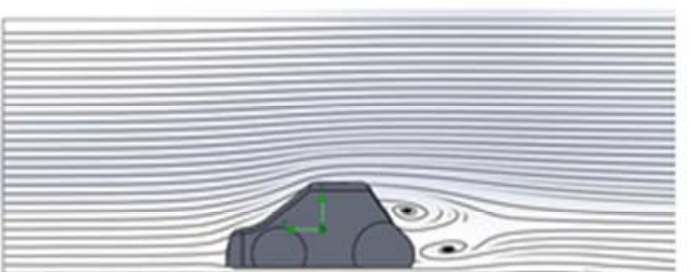

Magnets

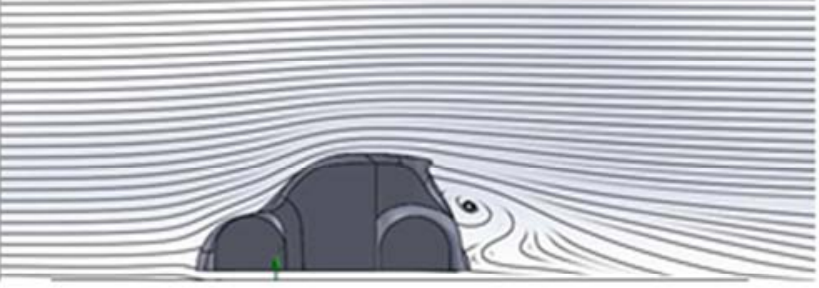

Bluris

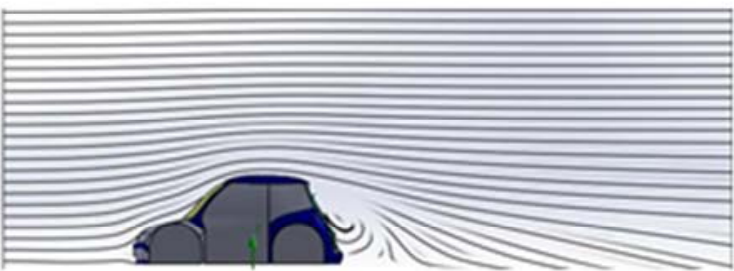

Vectra

Figure 2. Solidworks velocity stream lines around different bodies at $V=30 \mathrm{~m} / \mathrm{s}$.

Figure 3 shows 3D pressure contours around different bodies design and the recorded results show that the VECTRA design is chosen due to reasonable pressure distribution values.
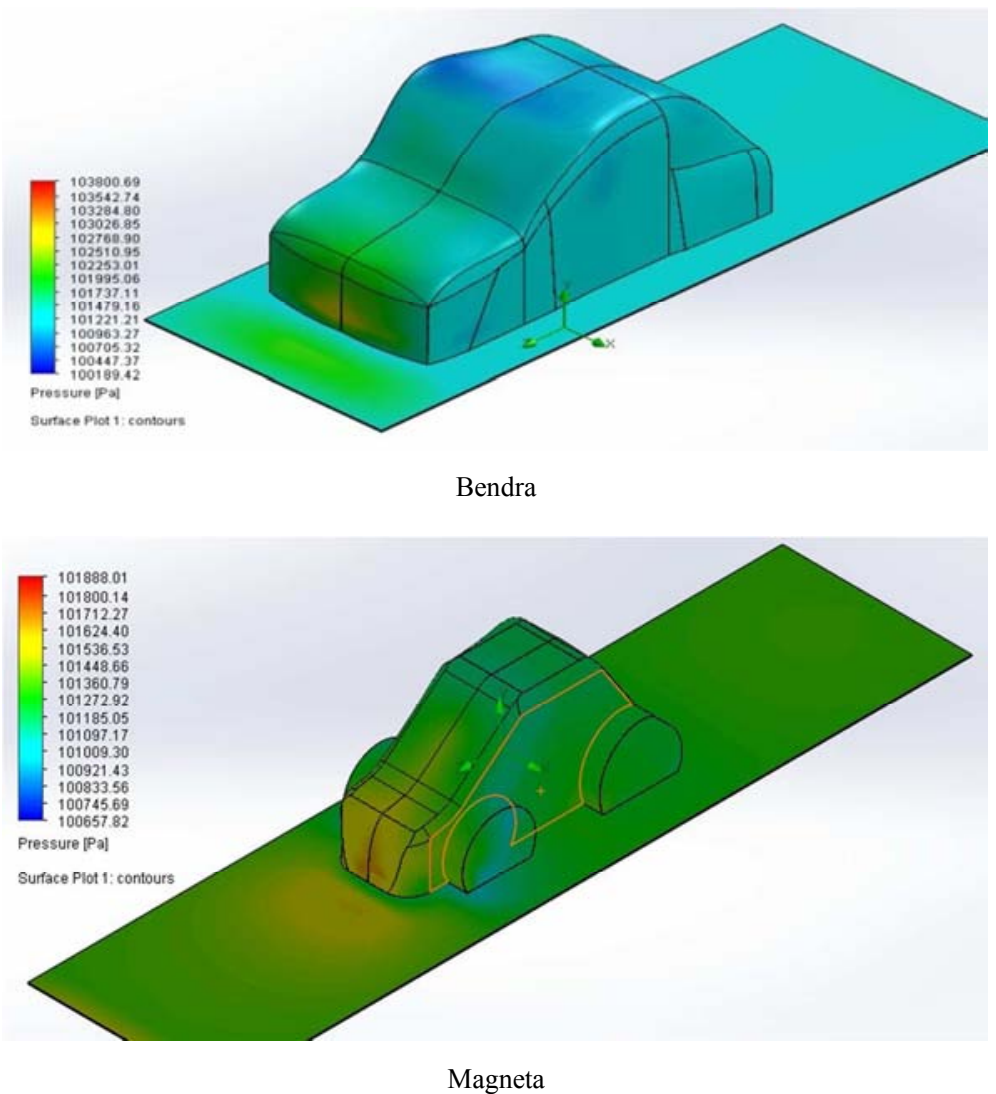


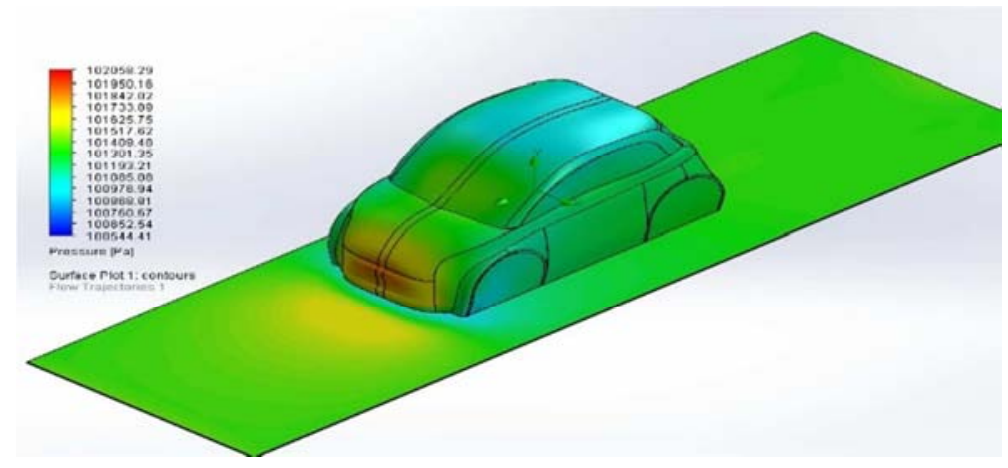

Violet

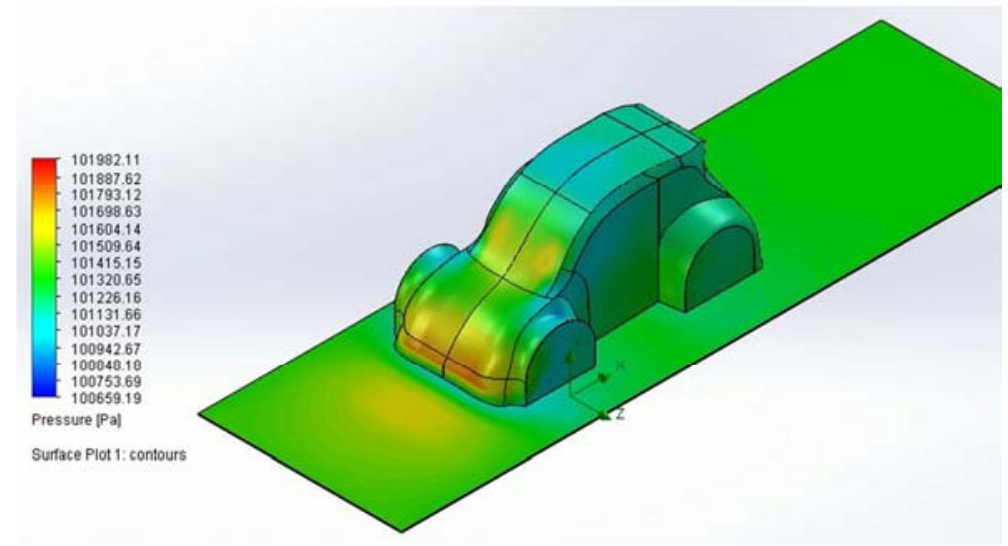

Bluria

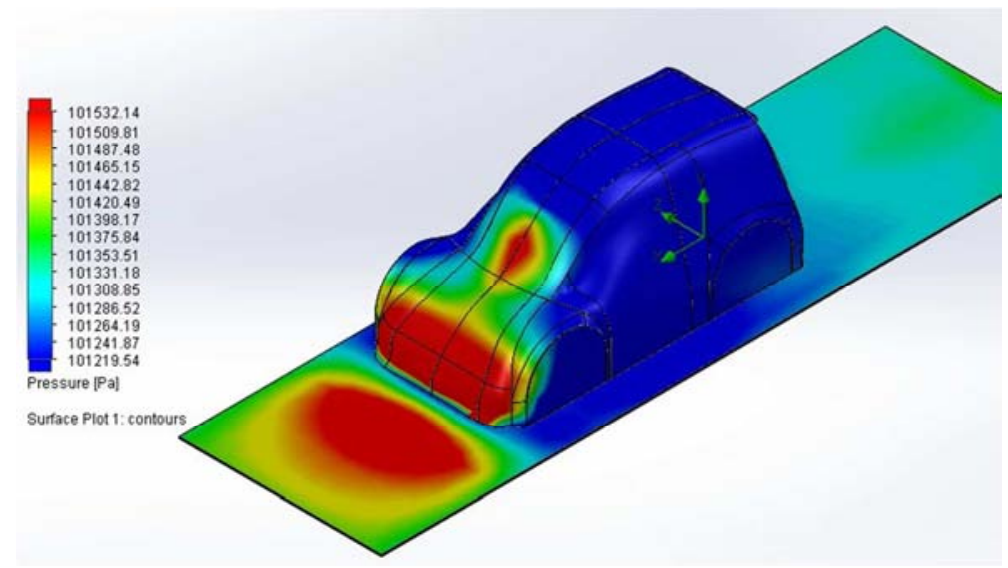

Aqua

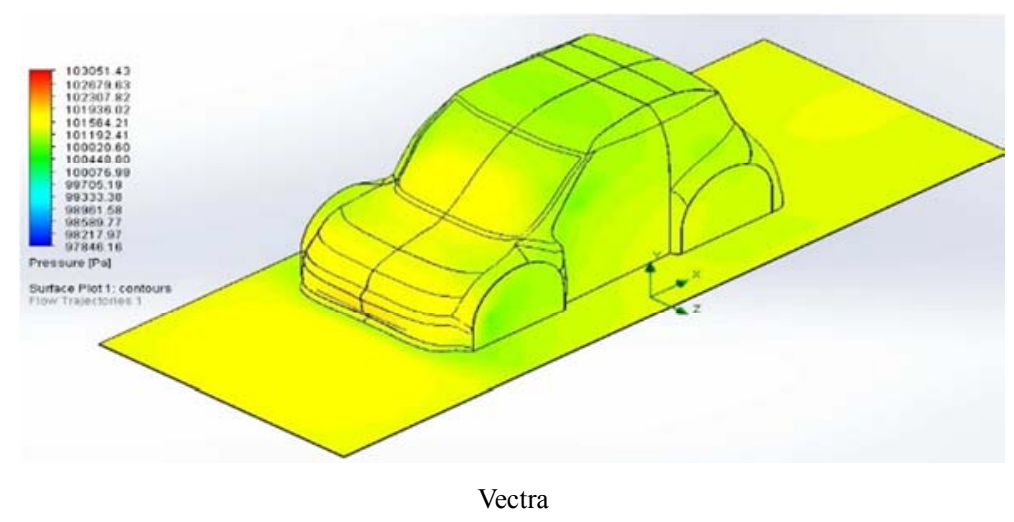

Figure 3. Solidworks pressure contours around different bodies at $V=30 \mathrm{~m} / \mathrm{s}$. 
Figure 4 shows 3D density contours around different bodies design and the results show that the VECTRA design is chosen due to reasonable density distribution values that matches with pressure distribution and velocity profiles.

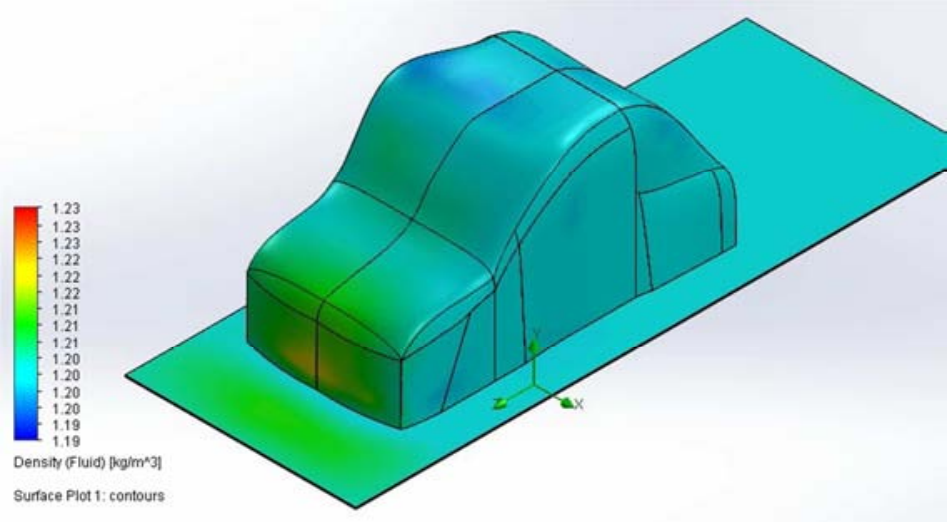

Bendra

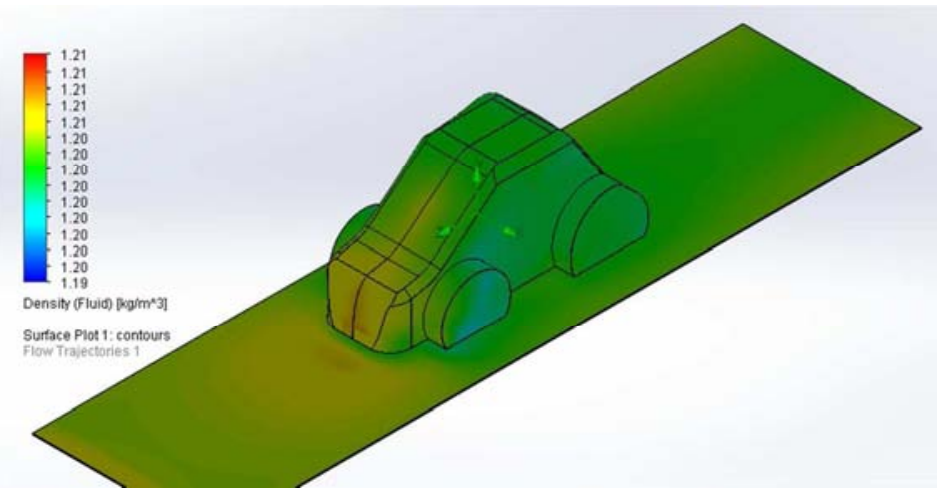

Magneta
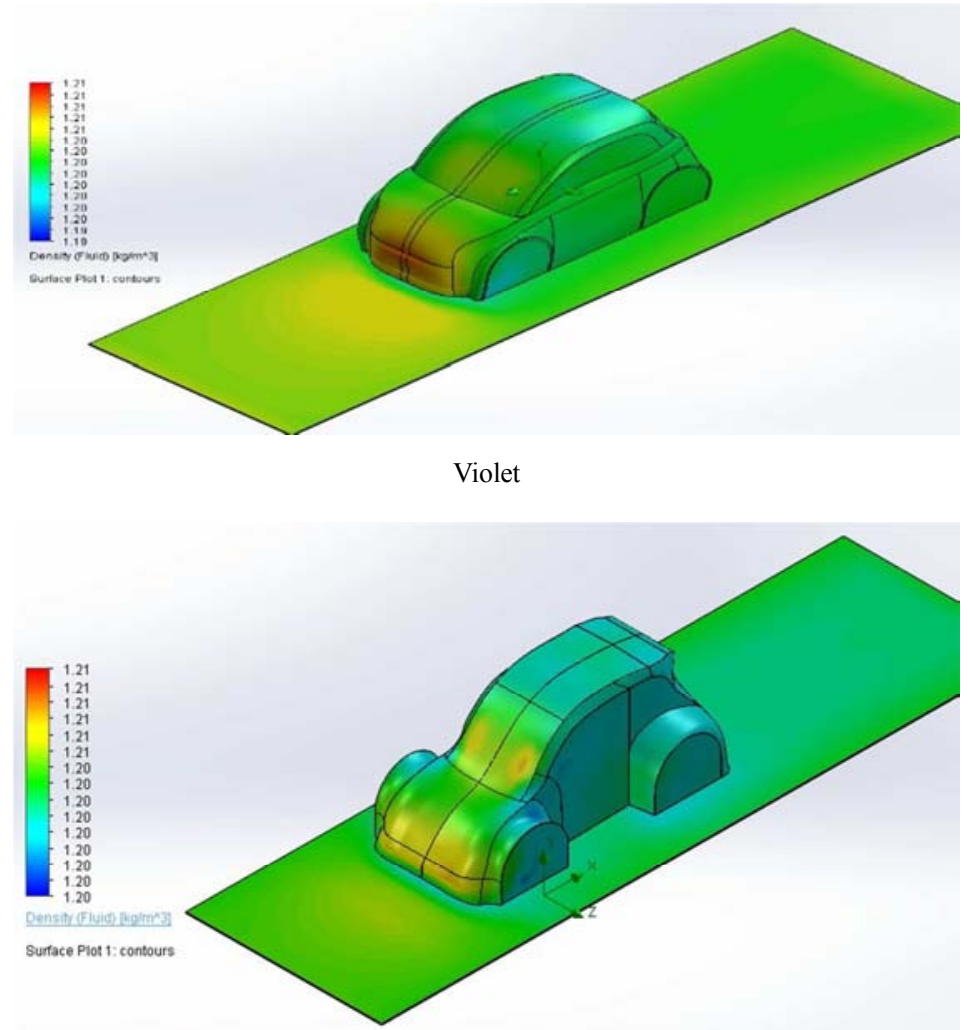

Bluria 


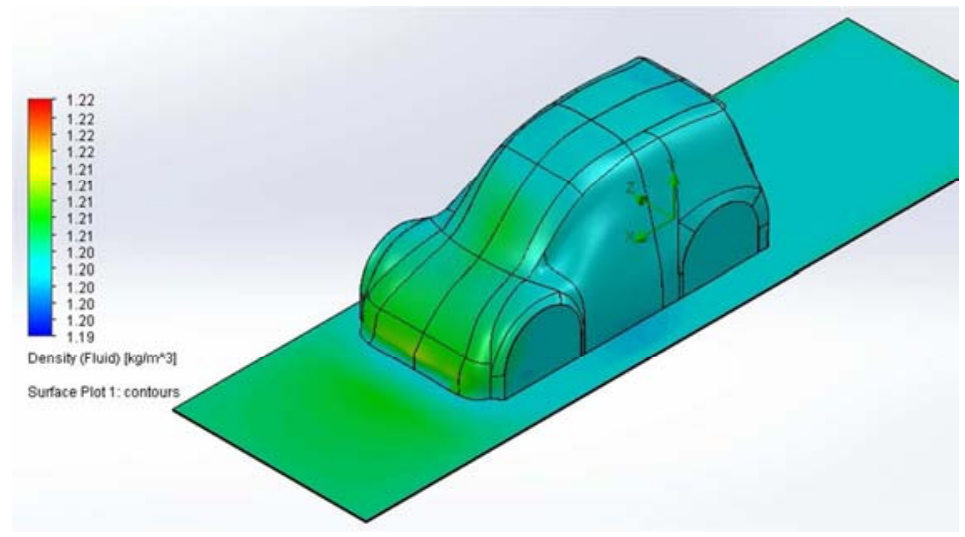

Aqua

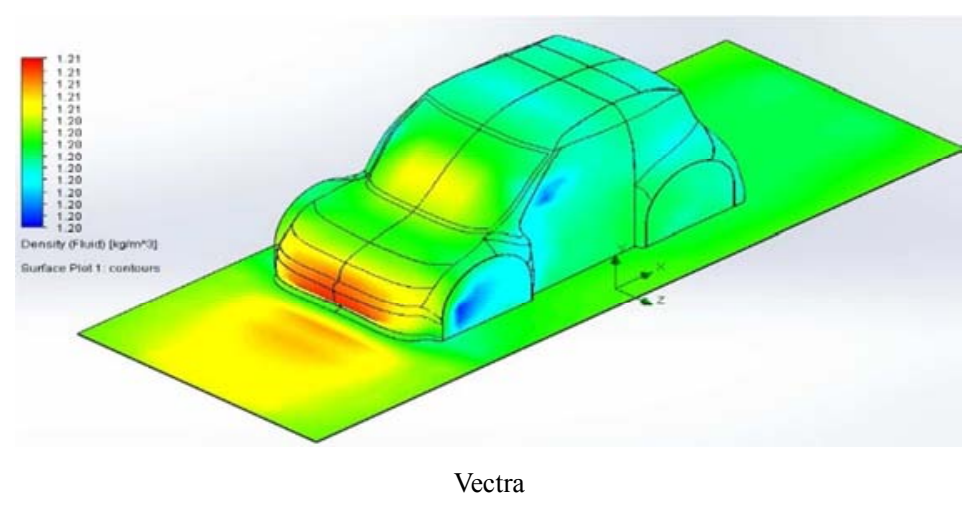

Figure 4. Solidworks density Contours around different bodies at $V=30 \mathrm{~m} / \mathrm{s}$.

Figure 5 shows velocity flow trajectories around different bodies design and the results show that the VECTRA design is chosen due to matching results between velocity stream lines profile and velocity flow trajectories.

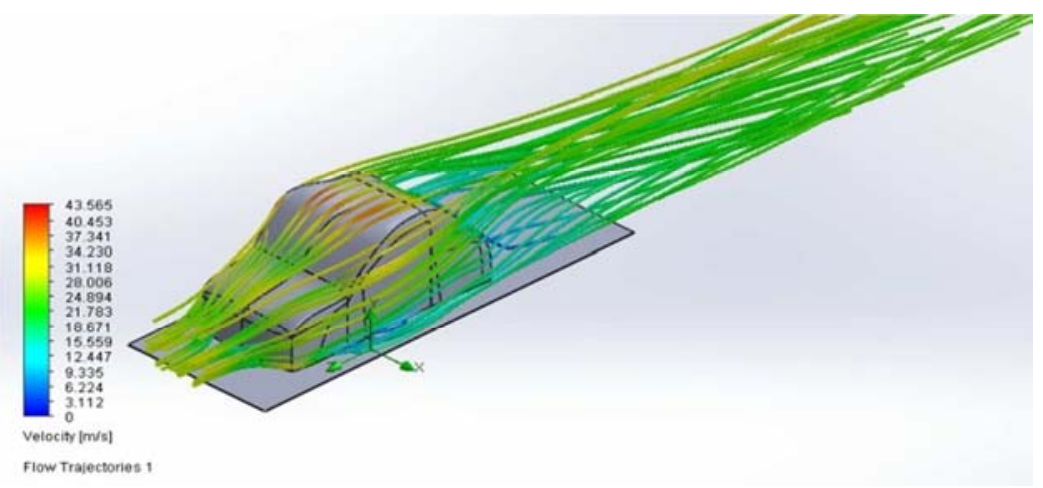

Bendra

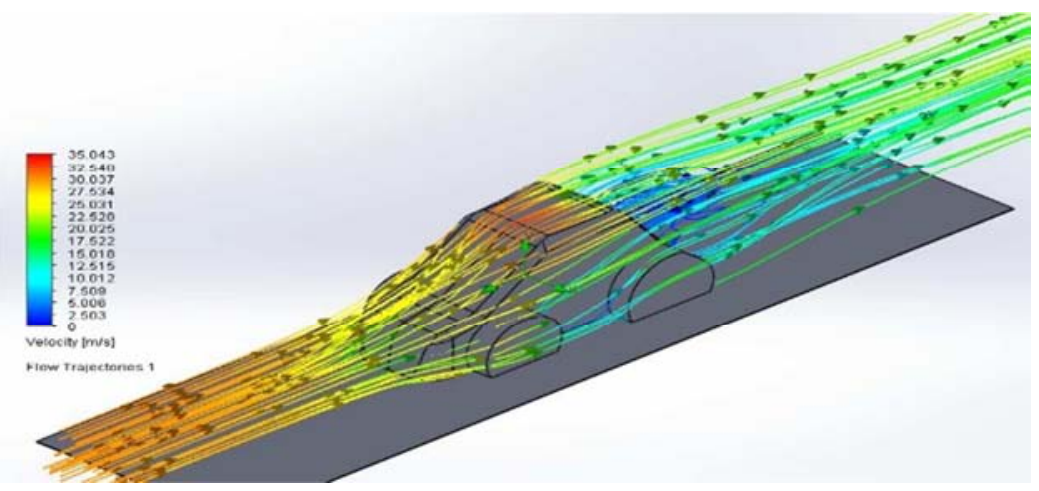

Magneta 

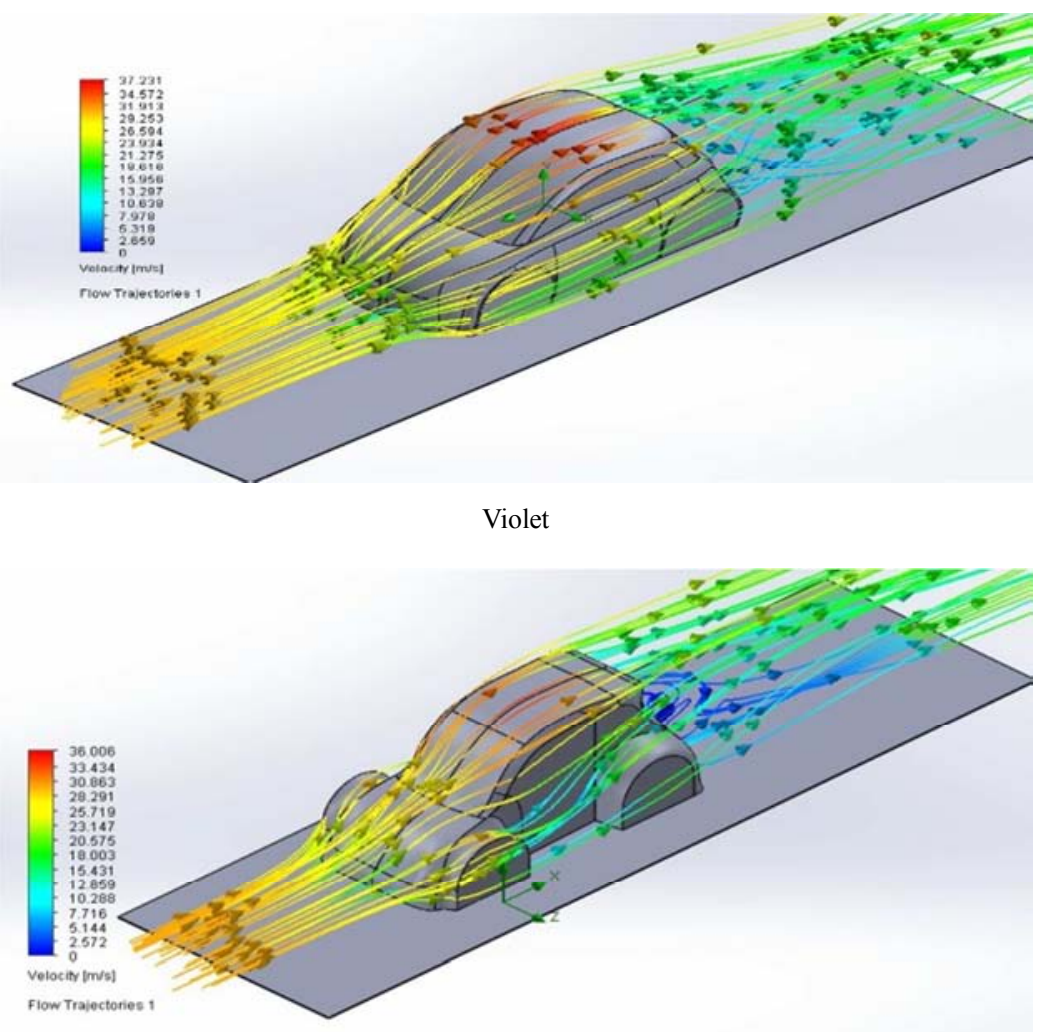

Bluria

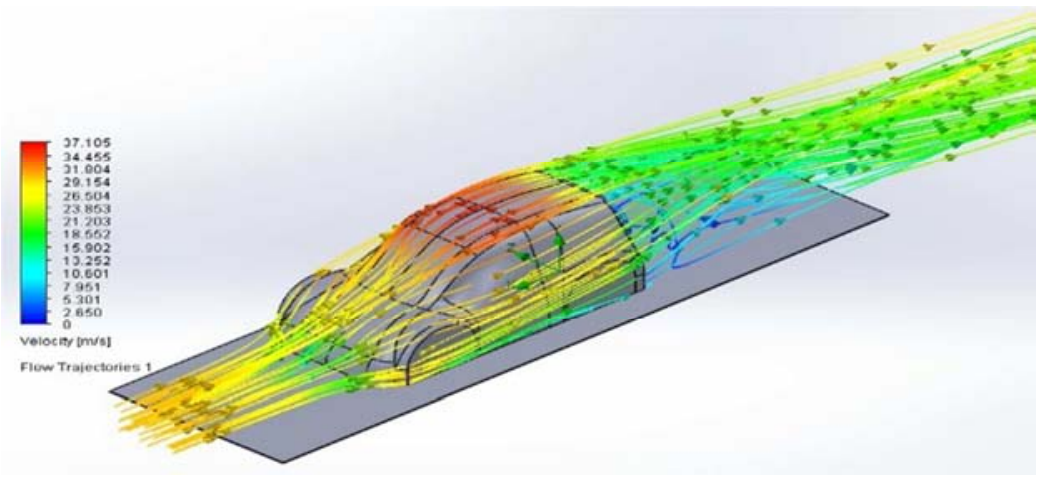

Aqua

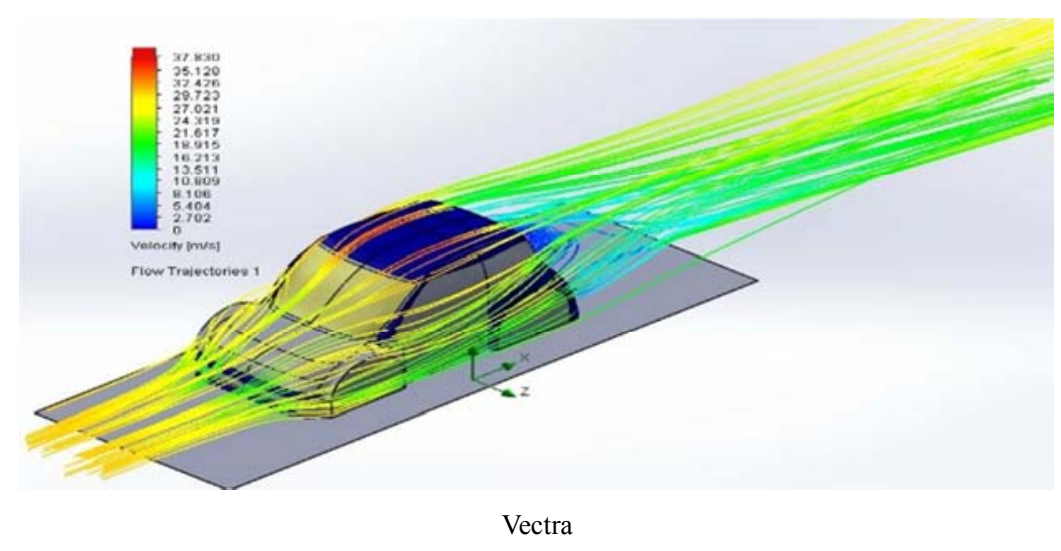

Figure 5. Solidworks velocity flow trajectories around different bodies at $V=30 \mathrm{~m} / \mathrm{s}$.

Figure 6 shows the relation between the power consumption and the velocity from zero to $30 \mathrm{~m} / \mathrm{s}$. this plot presents the comparison between the six models of the urban electric vehicle of these parameters. Its shows that the top 
model of energy consumption is BENDRA model about 15 KW and the least energy-consuming model is VECTREA about $9 \mathrm{KW}$. The plot also shows that the consumed energy values are very close at low speeds up to $40 \mathrm{~km} / \mathrm{h}$, however, the difference then widens up to $120 \mathrm{~km} / \mathrm{h}$.

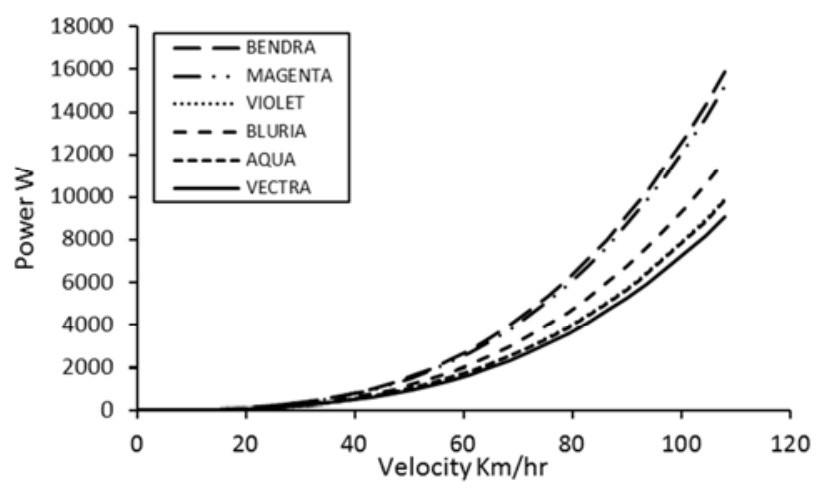

Figure 6. Power versus velocity of different bodies.

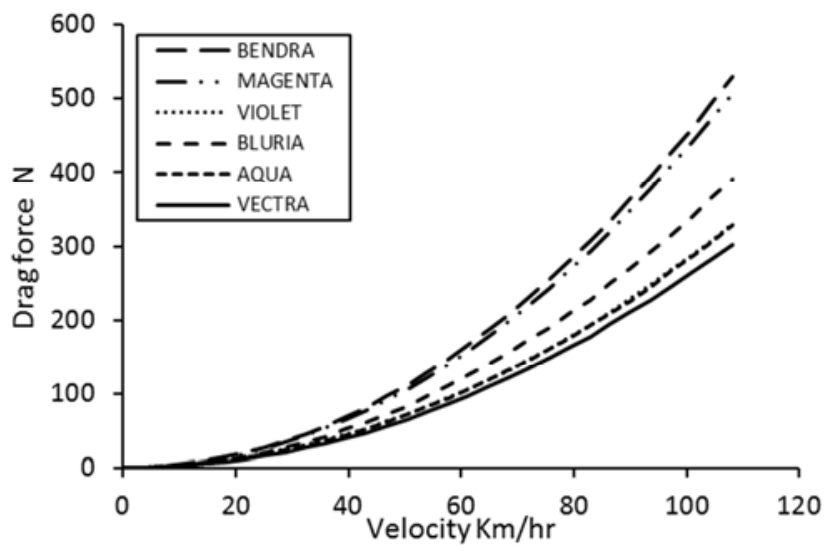

Figure 7. Drag force versus velocity of different bodies.

Figure 7 shows the relation between the drag force and the velocity from zero to $30 \mathrm{~m} / \mathrm{s}$. this plot presents the comparison between the six models of the urban electric vehicle of these parameters. Its shows that the top model of drag force is BENDRA model about $550 \mathrm{~N}$ and the least drag force model is VECTREA about $250 \mathrm{~N}$. The plot also shows that the drag force values are very close at low speeds up to $40 \mathrm{~km} / \mathrm{h}$, however, the difference then widens up to 120 $\mathrm{km} / \mathrm{h}$.

\subsection{Ansys Simulation}

Table 4 shows that the final results of the six model which simulated in ANSYS fluent at $\mathrm{V}=30 \mathrm{~m} / \mathrm{s}$.

Table 4. Vehicle models results with ANSYS

\begin{tabular}{lllll}
\hline & $\begin{array}{l}\text { Frontal } \\
\text { area }^{\mathbf{2}}\end{array}$ & Cd & $\begin{array}{l}\text { Drag area } \\
\mathbf{m}^{\mathbf{2}}\end{array}$ & Power W \\
\hline BENDRA & 1.54 & 0.70197 & 1.081034 & 17877.61 \\
MAGENTA & 1.22 & 0.811165 & 0.989622 & 16365.87 \\
VIOLET & 1.43 & 0.414178 & 0.592275 & 9794.751 \\
BLURIA & 1.22 & 0.646264 & 0.788442 & 13038.86 \\
AQUA & 1.3 & 0.465038 & 0.604549 & 9997.736 \\
VECTRA & 1.37 & 0.39712 & 0.544054 & 8997 \\
\hline
\end{tabular}

The power data for the six models presented in Table 4 shows that the most effective model in power consumption is the VECTRA model. Which mean that when the VECTRA model go on the road at $\mathrm{V}=30 \mathrm{~m} / \mathrm{s}$, the power consumption will be about $9 \mathrm{KW}$. The nearest models are AQUA model with $10 \mathrm{KW}$ and VIOLET model with $9.8 \mathrm{KW}$. The flow simulation has been done in ANSYS fluent for the six vehicle car models under specific parameters such as, velocity is 30 $\mathrm{m} / \mathrm{s}$ and the density of air is $1.225 \mathrm{~kg} / \mathrm{m}^{3}$. The turbulence model used in this study is "Viscous - Realizable K- $\varepsilon$, Scalable wall Fn". This model recommended by many designers and researchers in the field of CFD which this model able to reach more accurate solution for the CFD field. Figure 8 and Figure 9 show the ANSYS fluent velocity streamlines and pressure contours of different models at velocity $30 \mathrm{~m} / \mathrm{s}$.

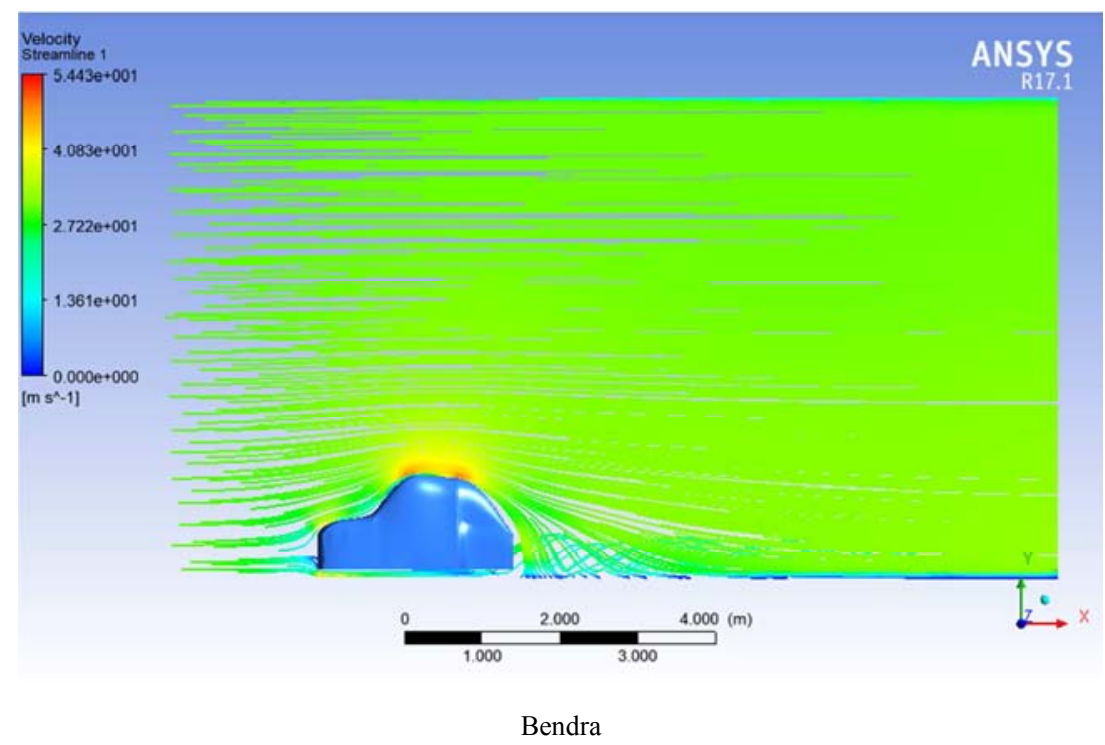




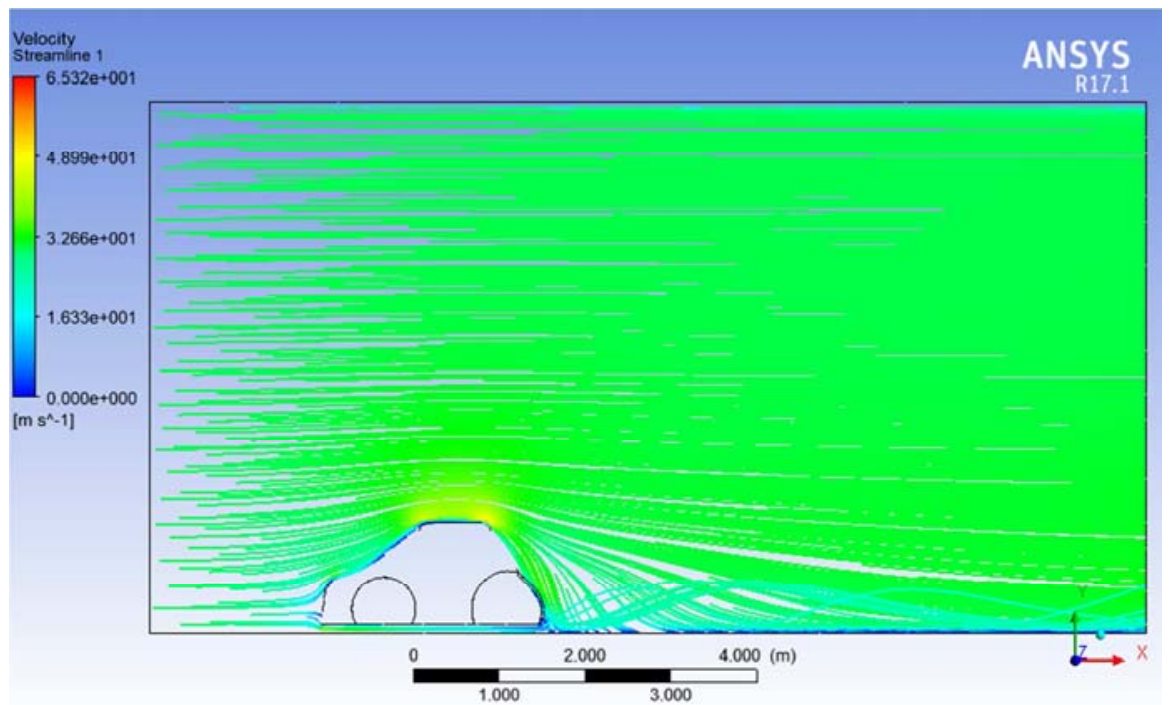

Magneta

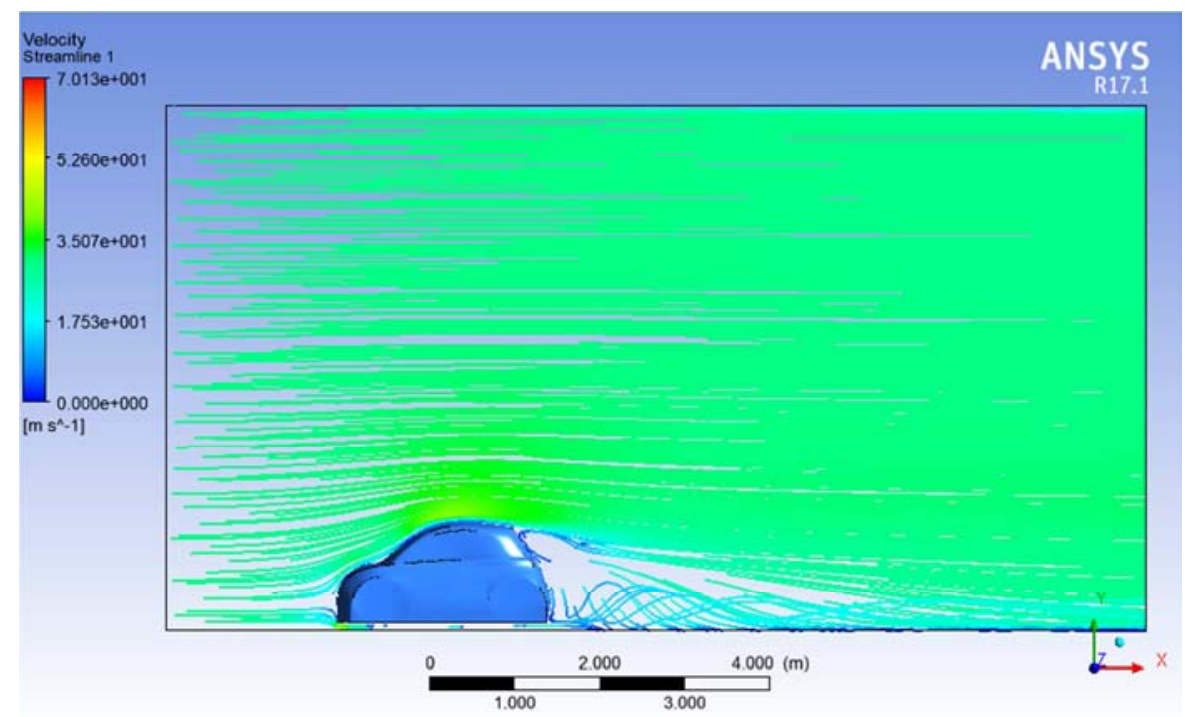

Violet

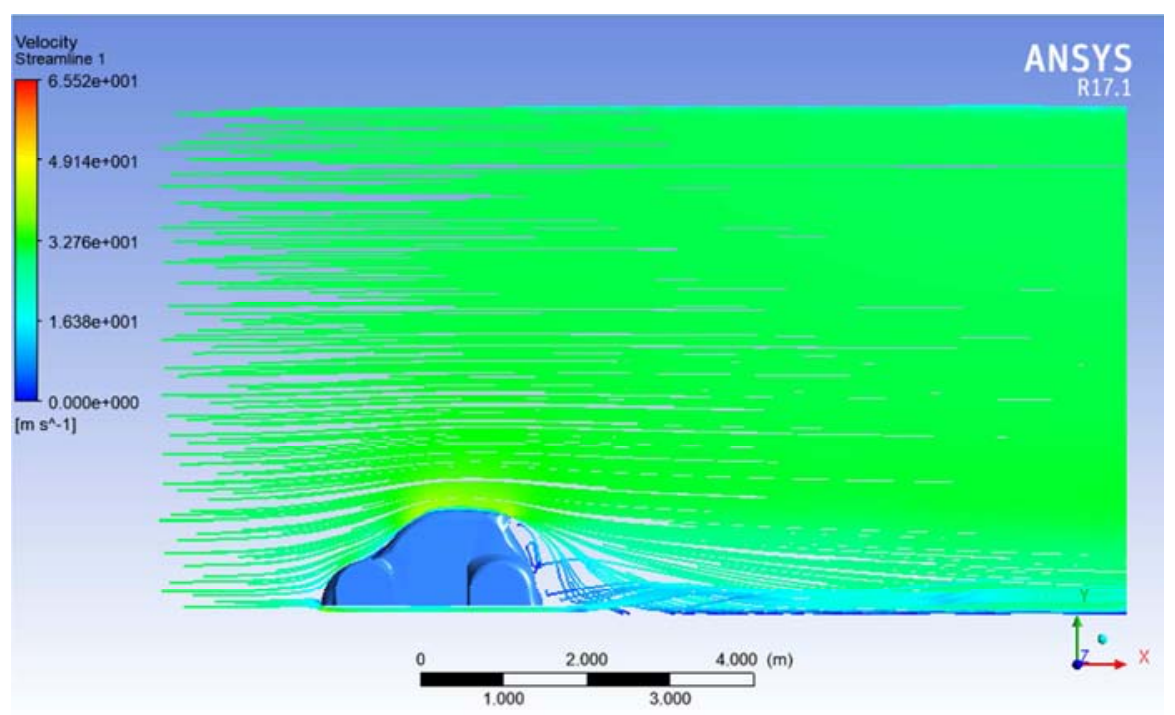

Bluria 


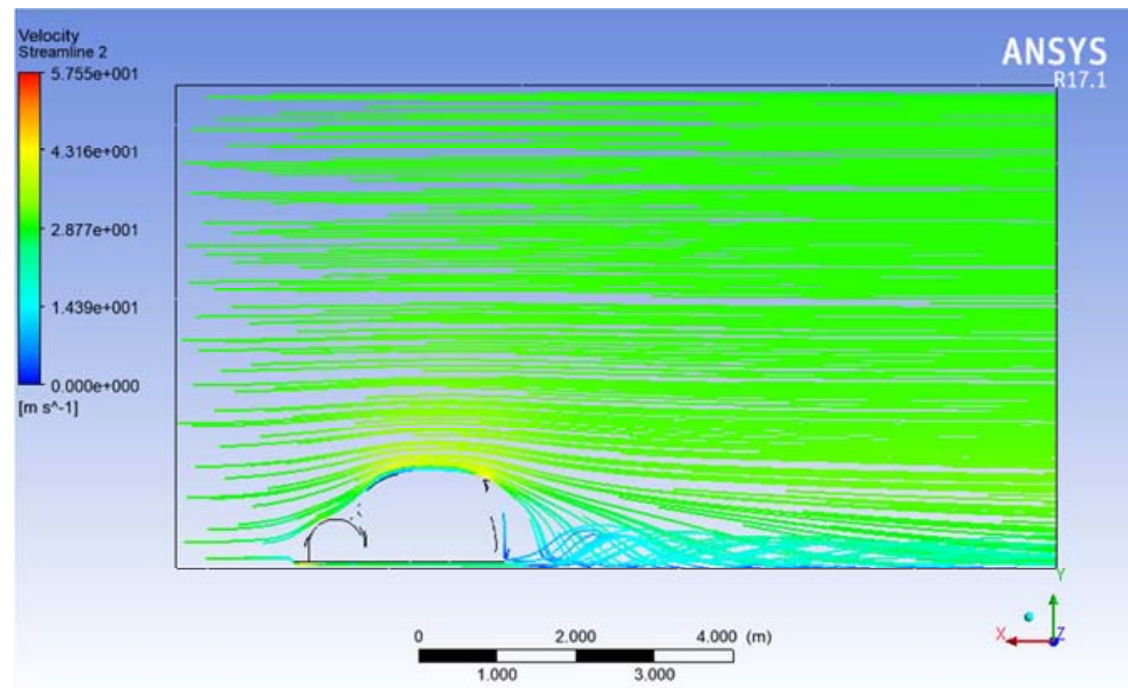

Aqua

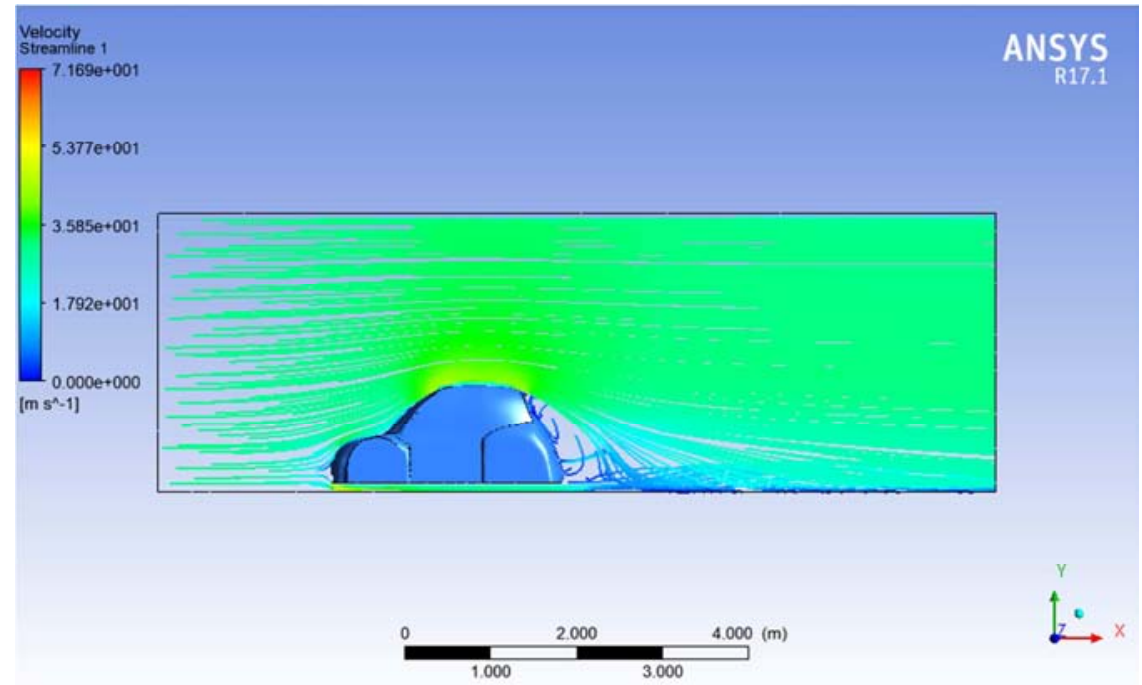

Vectra

Figure 8. ANSYS fluent Velocity streamlines around different bodies at $\mathrm{V}=30 \mathrm{~m} / \mathrm{s}$

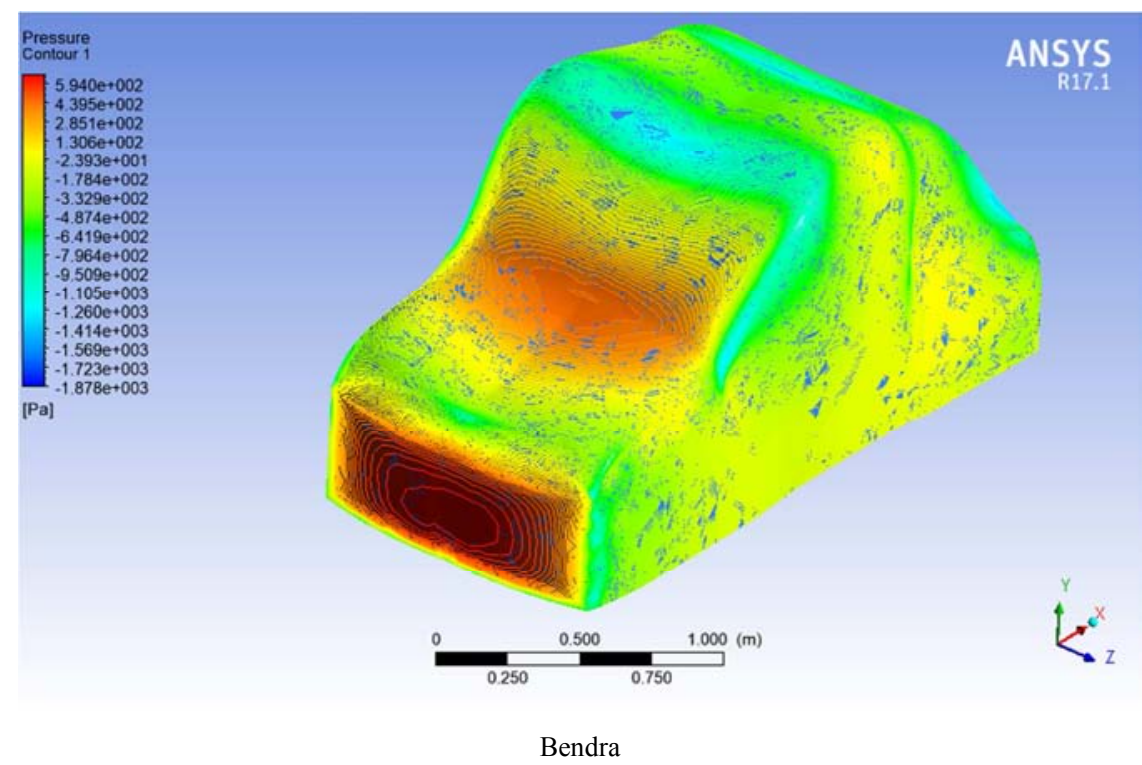



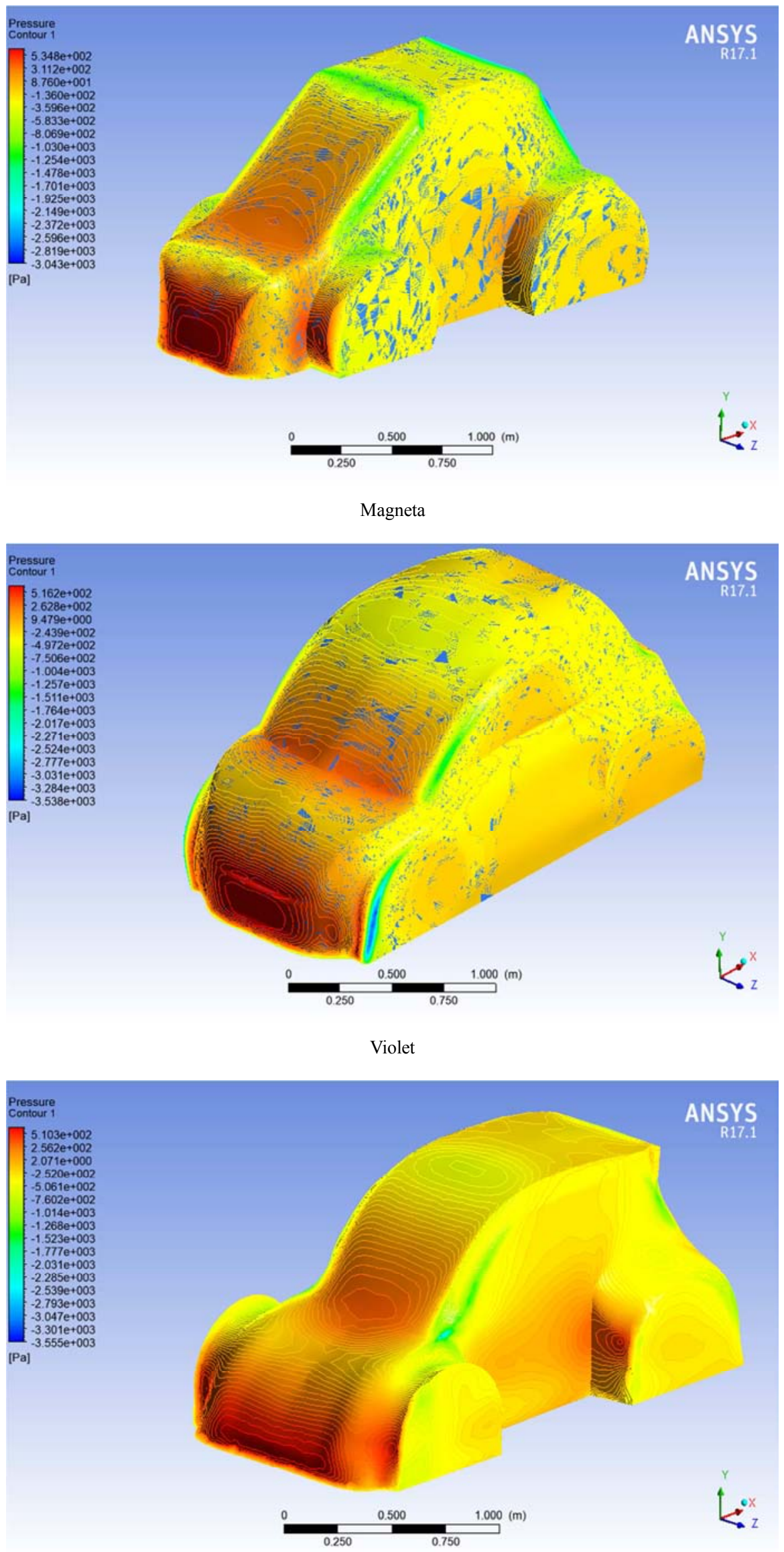

Bluria 

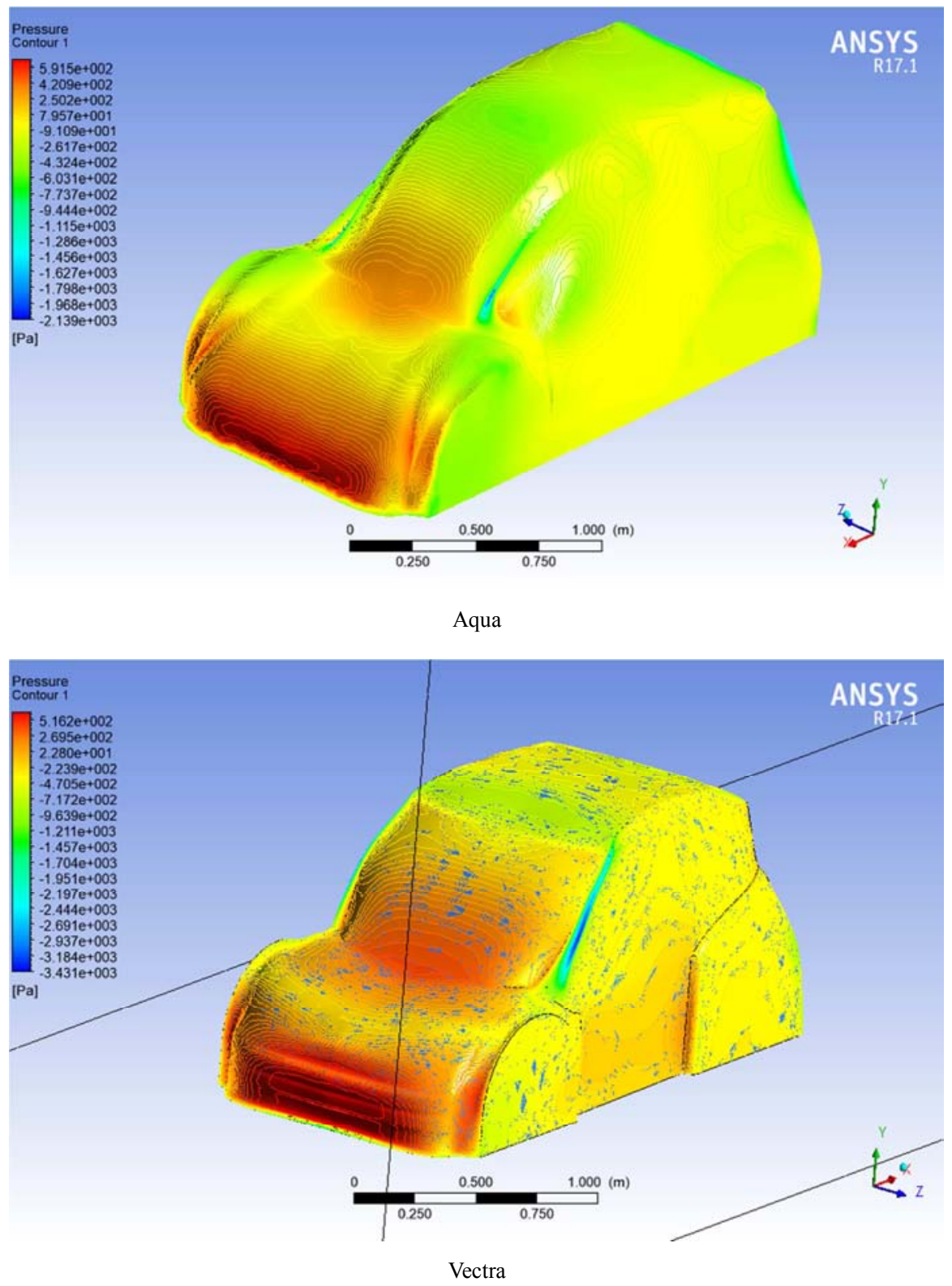

Figure 9. ANSYS fluent pressure contours around different bodies at $V=30 \mathrm{~m} / \mathrm{s}$.

\section{Experimental Analysis Using Wind Tunnel}

An experimental verification is done to check the validity of the proposed theoretical design. The experimental analysis is done on $3 \mathrm{D}$ printed of the best effective model inside open wind tunnel. After the best effective vehicle body model has been chosen, this model has been 3D printed using 3D printer with scale 1: 25 from the original model. The scaled model has been tested in open wind tunnels called "HM 170 open wind tunnel".

HM 170 is an open wind tunnel used to demonstrate and measure the aerodynamic properties of 3D printed vehicle model. For this purpose, air is drawn in from the environment and accelerated. The air flows around a model in a measuring section. The air is then decelerated in a diffuser and pumped back.
The carefully designed nozzle contour and a flow straightener ensure a uniform velocity distribution with little turbulence in the closed measuring section. The flow cross-section of the measuring section is square. Air velocities up to $28 \mathrm{~m} / \mathrm{s}$ can be reached in this open wind tunnel. The tunnel is equipped with an electronic two-component force sensor. Lift and drag are detected and displayed digitally. Wind tunnel equipped with inclined tube manometers (HM 170.50), the electronic pressure measurement (HM 170.55) and data acquisition (HM 170.60) to measure the values of velocity, forces, moment, displacement/angle, and differential pressure. These recorded values are transferred to a PC where they can be analyzed.

Figure 10 and Figure 11 show one of the key advantages of $3 \mathrm{D}$ printing is the ability to produce very complex shapes or geometries, and a prerequisite for producing any $3 \mathrm{D}$ printed part is a digital 3D model or a CAD file.

So in this study VECTRA model has been chosen as a best 
effective vehicle body model and $3 \mathrm{D}$ printed with scale of 0.04 from the original model. Figure 10 shows VECTRA model after printed and shows that there are no different between 3D printed model and the CAD model.

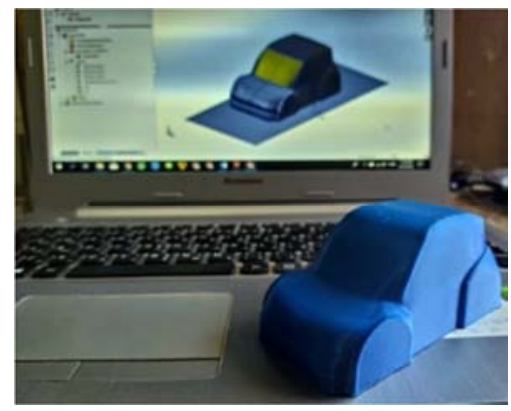

Figure 10. VECTRA 3D printed model and CAD model.

The experimental procedures in the wind tunnel as follow; First step is to fix the 3D printed model in the open wind tunnel as shown in Figure 11, this step is important to reach the accurate values. The model must be in the opposite direction of the air flow and must be parallel to the ground plate.

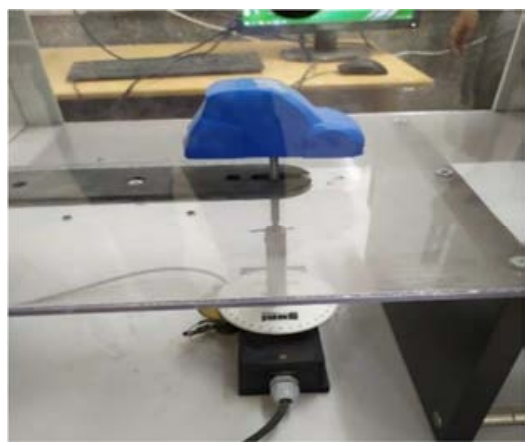

Figure 11. VECTRA 3D printed model setup

To make the model in front of the air flow, the fixation angle must be at zero degree, this angle guarantee that the model to be in opposite direction of the air flow.

To get accurate results from the open wind tunnel, the following data show in in Table 5 are used. There are two main changes from the CFD study parameters, the first one is the velocity range, in this type of the open wind tunnel the maximum velocity is $23 \mathrm{~m} / \mathrm{s}$. so the range of the velocity will be from zero to $23 \mathrm{~m} / \mathrm{s}$. The second one is the domain volume, in the open wind tunnel the domain volume is $0.3 \mathrm{~m} * 0.3 \mathrm{~m} * 0.3 \mathrm{~m}$.

Table 5. Wind tunnel study parameters.

\begin{tabular}{ll}
\hline Unit system & SI $(\mathbf{m} / \mathbf{k g} / \mathbf{s})$ \\
\hline Pressure & $101325 \mathrm{~Pa}$ \\
Temperature & $293.2 \mathrm{k}$ \\
Velocity range & $0-23 \mathrm{~m} / \mathrm{s}$ \\
Flow type & Laminar and turbulent \\
Analysis type & External flow \\
Size of computational domain & $0.3 \mathrm{~m} * 0.3 \mathrm{~m} * 0.3 \mathrm{~m}$ \\
\hline
\end{tabular}

As shown in Figure 12 Vectra model has been fixed in the open wind tunnel and the results has been taken from the pc screen.

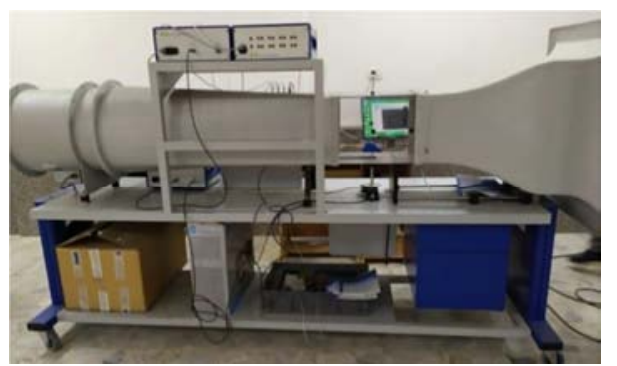

Figure 12. VECTRA during wing tunnel test.

\section{VECTRA Results with Wind Tunnel}

The test of the model in the open wind tunnel has been done in different velocities according to the wind tunnel velocity limit. The velocity range is between zero to $23 \mathrm{~m} / \mathrm{s}$, and the results of this test presented in pc screen connected with the open wind tunnel.

Due to wind tunnel velocity accuracy, the range of velocity be from about $5 \mathrm{~m} / \mathrm{s}$ to $23 \mathrm{~m} / \mathrm{s}$, and the total points taken from the device are twelve points.

The flow test in HM 170 open wind tunnel has been done in specific parameters on VECTRA model as a best effective model, so the next table 6 shows that the final results of the VECTRA model test which simulated in HM 170 open wind tunnel at $\mathrm{V}=23 \mathrm{~m} / \mathrm{s}$.

Table 6. VECTRA model analytical and experimental results.

\begin{tabular}{llll}
\hline & Wind tunnel & ANSYS & Solidworks \\
\hline Frontal area $\mathrm{m}^{2}$ & 0.0035 & 1.37 & 1.37 \\
Cd & 0.434538 & 0.39712 & 0.400757 \\
Drag area $\mathrm{m}^{2}$ & 0.001521 & 0.544054 & 0.549038 \\
\hline
\end{tabular}

Table 6 shows that the drag coefficient of the VECTRA model in the open wind tunnel is close to the results of ANSYS and Solidworks, and the difference between them is less than $10 \%$ between wind tunnel and ANSYS fluent results, and less than $9 \%$ between wind tunnel and Solidworks flow simulation results. These results and different between wind tunnel and software results are acceptable due to many errors of the experimental test such as, Manufacturing accuracy, setup errors and measurement and sensors errors.

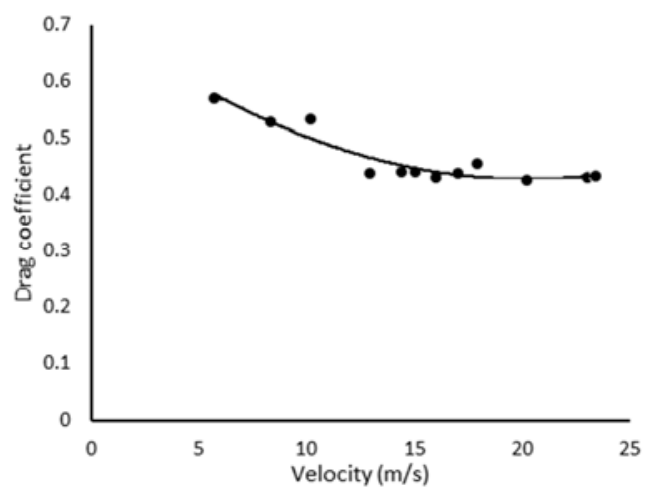

Figure 13. Experimental and numerical drag coefficients of Vectra model. 
Figure 13 shows that the drag coefficient starts high at the beginning of moving at low velocities and decrease gradually with increase of velocity until the effect of velocity variation is very small on the drag coefficient. The experimental and CFD results are nearly in agreement. The increase of the drag coefficient in the beginning of moving due to the high resistance of air flow to the vehicle, then the vehicle overcome this resistance at high speeds.

\section{Comparison Between VECTRA and Real Cars}

As shown that the VECTRA car model is the best effective model on power consumption between the six vehicles body models. So the next step is to compare this model with the real car bodies on power consumption. Figure 14 shows the different real car bodies specifications.

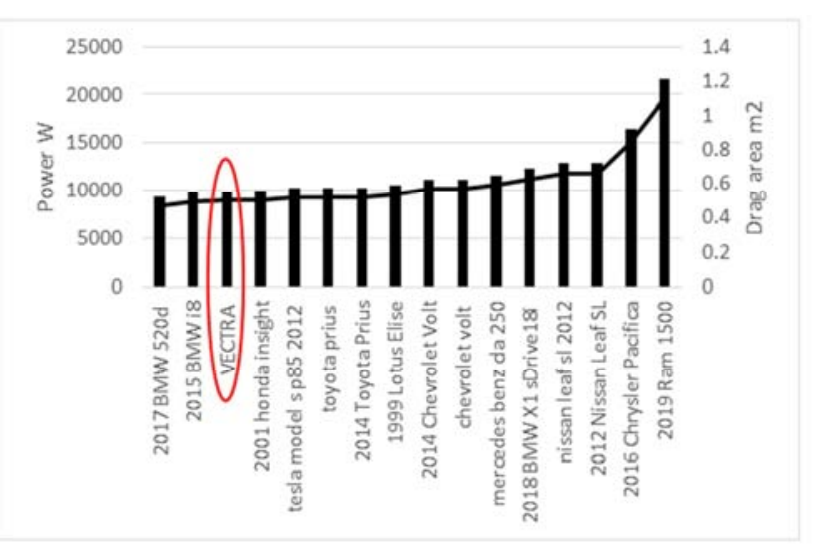

Figure 14. VECTRA versus real cars.

As we show in Figure 14 that the VECTRA model is a competitor for the real car bodies and consumes less energy than many cars like BMW, Mercedes, and Tesla whether the cars using internal combustion engine or electric motors.

\section{Conclusion}

The aerodynamic performance of today's vehicles has not yet reached its fully potential. With new technologies and innovations more and more aerodynamic features are implemented in the vehicle design.

In this study, different aerodynamic features have been emphasized. It's found that the frontal area is not the important factor to decrease the drag coefficient, and also not factor to decrease the power consumption. But the main factor to decrease it is to decrease the drag area of the body. This lead to decrease the power consumption in different velocities. The models that have low frontal area, don't the best effective models in power consumption side, such as MAGENTA model, it has $1.2 \mathrm{~m}^{2}$ frontal area but it consumes the highest energy compared to other models about $15 \mathrm{KW}$. In other side, VECTRA model has about 1.29 $\mathrm{m}^{2}$ but it consumes less energy than other models about $9 \mathrm{KW}$.
The performance of aerodynamic features is only valid for the specific vehicle model it have been developed for. Transferring the feature to another vehicle model will in most cases not give the same performance and must be further studied for full efficiency.

\section{References}

[1] Rezvani, Z., Jansson, J., and Bodin J. “Advances in consumer electric vehicle adoption research: A review and research agenda" Transportation Research Part D: Transport and Environment, Volume 34, 2015, pp. 122-136.

[2] Arnold kuethe and chuen-yen chow, "Fundamental of aerodynamics" fifth edition, New York, 1998.

[3] William Milliken and Douglas Milliken, "Race car vehicle dynamics" fifth edition, USA, 1995.

[4] David Crolla, "Automotive Engineering" first edition, USA, 2009.

[5] Joseph Katz, "Race Car Aerodynamics" RE 2nd edition, USA, 1995.

[6] WANG, Q., WU, Z., ZHU, X., LIU, L. and ZHANG, Y. "Analysis of Aerodynamic Performance of Tesla Model S by CFD" 3rd Annual International Conference on Electronics, Electrical Engineering and Information Science (EEEIS 2017).

[7] Gupta, S., and Saxena, K. "AERODYNAMICS ANALYSIS OF A FORMULA SAE CAR" 13th International Conference on Heat Transfer, Fluid Mechanics and Thermodynamics.

[8] JANSON, T., and PIECHNA J. "Numerical Analysis of Aerodynamic Characteristics of a High-Speed Car With Movable Bodywork Elements" Archive of Mechanical Engineering, 2015.

[9] WANG, X., LIU, J. and DENG Y. "The Effect on Aerodynamic Performance of Electric Vehicle Caused by Battery Pack Installed in the Chassis" International Conference on Manufacturing Science and Information Engineering (ICMSIE 2016).

[10] Ravelli, U., and Savini, M. "Aerodynamic Simulation of a 2017 F1 Car with Open-Source CFD Code" Journal of Traffic and Transportation Engineering 6, 2018, 155-163.

[11] Siva, G., and Loganathan V. "Design and Aerodynamic Analysis of a Car to Improve Performance" Middle-East Journal of Scientific Research, 133-140, 2016.

[12] Parab, A., Sakarwala, A., Paste, B. Patil, V. "Aerodynamic Analysis of a Car Model using Fluent- ANSYS 14.5" International Journal on Recent Technologies in Mechanical and Electrical Engineering (IJRMEE), Vol 1, ISSUE 4, 2014, pp. 7-13.

[13] Purevsuren, E., and Tian, D. "Aerodynamic CFD study of Wortmann FX66-S-196 Airfoil" International Journal of Engineering Research \& Technology (IJERT), Vol 7, ISSUE 4, 2018, pp. 590-594.

[14] Czyż, Z., Karpiński, P., Gęca, M., Ulibarrena, J. “THE AIR FLOW INFLUENCE ON THE DRAG FORCE OF A SPORTS CAR" Advances in Science and Technology Research Journal, Vol 12, No. 2, 2018, pp. 121-127. 
[15] Vaidya, S., and Kulkarni, C. "Aerodynamic Development of a Formula SAE Car: Initial Design Stage" International Journal of Engineering Research \& Technology (IJERT), Vol 6, ISSUE 12, 2017, pp. 14-18.

[16] Taherkhani AR, deBoer GN, Gaskell PH, Gilkeson CA, Hewson RW, "Aerodynamic Drag Reduction of Emergency Response Vehicles" Adv Automob Eng 4: 122, 2015, doi: 10.4172/2167-7670.1000122.

[17] Cieslinski, A., Prym, W., Stajuda M. and Witkowski D. "Investigation on Aerodynamics of Super-Effective Car for Drag Reduction" Mechanics and Mechanical Engineering, Vol. 20, No. 3, 2016, 295-308.

[18] Yuan, Z., and Wang, Y. "Effect of underbody structure on aerodynamic drag and optimization" Journal of Measurements in Engineering, Vol. 5, Issue 3, 2017, p. 194-204.

[19] Rakibul, S., Islam, T., Ali, M., and Islam Q. "Numerical Study on Aerodynamic Drag Reduction of Racing Cars", 10th International Conference on Mechanical Engineering, ICME 2013.

[20] Singla, D., Tayal, A., Sharma, R., Kesari, D. "Aerodynamic Development of a Solar Car" International Journal of Engineering Research \& Technology (IJERT), Vol 4, ISSUE 6, 2015, pp. 371-376.

[21] Shivam, Singh, S., Guleria, A. and Mukkamala, Y. "Aerodynamic Drag Reduction of a Notchback Car Geometry by Delaying Flow Separation using Vortex Generators" International Journal of Engineering Research \& Technology (IJERT), Vol 4, ISSUE 8, 2015, pp. 521-524.

[22] Damissie, H., and Babu, N. "Aerodynamic Drag Reduction on Locally Built Bus Body using Computational Fluid Dynamics (CFD): A Case Study at Bishoftu Automotive Industry" International Journal of Engineering Research \& Technology (IJERT), Vol 6, ISSUE 11, 2017, pp. 276-283.

[23] Patil, C., Shashishekar, K., Balasubramanian, A., Subbaramaiah, S. "Aerodynamic Study and drag coefficient optimization of passenger vehicle" International Journal of Engineering Research \& Technology (IJERT), Vol 1, Issue 7, 2012.
[24] Parmar, M., Panchal, D., and Panchal, T. "A Technical Review - Comparative Assessment of Aerodynamic Forces Generated Due to Wind Deflector of Passenger Car by CFD and Experimental Method" International Journal of Engineering Research \& Technology (IJERT), Vol 4, Issue 10, 2016.

[25] Howell, J., Passmore, M. and Tuplin, S., “Aerodynamic Drag Reduction on a Simple Car-Like Shape with Rear Upper Body Taper" SAE Int. J. Passeng. Cars - Mech. Syst. 6 (1): 2013, doi: 10.4271/2013-01-0462.

[26] Jessing, C., Stoll, D., Kuthada, T., \& Wiedemann, J. "New horizons of vehicle aerodynamics" Proceedings of the Institution of Mechanical Engineers, Part D: Journal of Automobile Engineering, 231 (9), 1190-1202, 2017.

[27] Pikula, B., Filipovic, I., and Kepnik, G, (2011). "RESEARCH OF THE EXTERNAL AERODYNAMICS OF THE VEHICLE MODEL", www.researchgate.net/publication/256078917.

[28] Pikula B., Mešić E., Hodžić M.: "Determination of Air Drag Coefficient of Vehicle Models", International congress "Motor Vehicles and Motors", 2008.

[29] Pal, S., Kabir, S. and Talukder, M. "AERODYNAMIC ANALYSIS OF A CONCEPT CAR MODEL" 3rd International Conference on Mechanical Engineering and Renewable Energy, 2015.

[30] Ahmad, N., Abo-Serie, E. and Gaylard, A. "Mesh optimization for ground vehicle Aerodynamics" CFD Letters, Vol 2, no. 1, 2010, pp. 54-65.

[31] Thabet, S., and Thabet, H. "CFD Simulation of the Air Flow around a Car Model (Ahmed Body)" International Journal of Scientific and Research Publications, Vol 8, Issue 7, 2018, pp. 517-524.

[32] Vishwakarma, Y., Saxena, M., and Nagrajan, P. “Aerodynamic Improvement of Car Body" International Journal of Engineering Research \& Technology (IJERT), Vol 3, ISSUE 6, 2014, pp. 1761-1763.

[33] Huminic, A., Huminic, G. "AERODYNAMIC STUDY OF A GENERIC CAR MODEL WITH WHEELS AND UNDERBODY DIFFUSER" International Journal of Automotive Technology, Vol. 18, No. 3, pp. 397-404 (2017). 